\title{
Diabetes Mellitus Prevalence in HIV Patients on Antiretroviral Therapy at Parirenyatwa Group of Hospitals Opportunistic Infections Clinic, Harare, Zimbabwe
}

\author{
Article by Pasipanodya Ian Machingura ${ }^{1}$, Adam Chindore \\ ${ }^{1} \mathrm{PhD}$ Public Health, Texila American University, Zimbabwe \\ E-mail: imachingura@yahoo.co.uk
}

\begin{abstract}
HIV patients have increased life expectancy due to the access to antiretroviral drugs treatment. However the increasing age comes with increased risk to non communicable diseases which include diabetes mellitus. However the prevalence of diabetes mellitus amongst HIV patients has not been extensively studied in Zimbabwe. Thus we sought to determine the prevalence of diabetes mellitus amongst HIV patients on antiretroviral therapy treatment attending Parirenyatwa Group of Hospitals Opportunistic Infections Clinic, Harare, Zimbabwe.

A cross-sectional study was conducted at Parirenyatwa Group of Hospitals Opportunistic Infections Clinic, Harare, Zimbabwe. All HIV patients (18 years and older) on antiretroviral therapy attending Parirenyatwa Group of Hospitals Opportunistic Infections Clinic during the study period were given information on the study. Only those who consented to participate in the study were recruited. Demographic data was obtained from patients by administration of questionnaires. Blood samples were collected for glycosylated haemoglobin analysis on a Mispa-i2 Chemistry Analyser.

A total of $60 \mathrm{HIV}$ patients on antiretroviral therapy were recruited into the study, 33 (55\%) were females and 27 (45\%) were males. The mean age was $43.48 \pm 10.3$ years. Majority of the patients (33.3\%) were on tenofovir, lamivudine and efavirenz. The prevalence of diabetes mellitus was $8.3 \%$.

Diabetes mellitus prevalence amongst the HIV patients on antiretroviral therapy treatment was $8.3 \%$. There is need for need to investigate the factors associated with diabetes mellitus in HIV patients on antiretroviral therapy treatment and confirm the prevalence in a study with a large sample size.
\end{abstract}

Keywords: Human Immunodeficiency Syndrome, antiretroviral therapy, diabetes mellitus

\section{Introduction}

The increased access to antiretroviral treatment has converted Human Immunodeficiency Virus (HIV) into a chronic disorder, allowing the patients with HIV to live longer. The increasing age also comes with an increased risk of non communicable disease (1). Non communicable diseases such as diabetes mellitus and cardiovascular disease are amongst the leading causes of premature morbidity and mortality in developed and developing countries (2).

There is some conflicting evidence regarding HIV infection as an independent risk factor for diabetes mellitus, some studies shows increased risk whilst others show no independent effect of HIV on diabetes mellitus or an inverse effect(3). Diabetes mellitus is a known complication of antiretroviral treatment, it is associated with exposure to some antiretroviral drugs (4).However the overall effect of current antiretroviral treatment on glucose metabolism is modest in most patients. The prevalence of diabetes mellitus amongst HIV infected patients range from 2 to $14 \%$ and varies according to composition of studied cohort, how diabetes mellitus diagnosis is ascertained and how diabetes mellitus risk factors are accounted for in the analysis(3). 
Texila International Journal of Public Health

Volume 5, Issue 1, Mar 2017

The success of antiretroviral therapy in controlling HIV replication and restoring the immunity has been tempered with the knowledge that metabolic diseases which include diabetes mellitus are increasing in incidence amongst people living with HIV (5). However the prevalence of diabetes mellitus amongst HIV patients has not been extensively studied in Zimbabwe. Thus we sought to determine the prevalence of diabetes mellitus amongst HIV patients on antiretroviral therapy treatment attending Parirenyatwa Group of Hospitals Opportunistic Infections Clinic, Harare, Zimbabwe.

\section{Methods}

\section{Ethical considerations}

The study was approved by the Joint Research Ethics Committee for the University of Zimbabwe, College of Health Sciences and Parirenyatwa Group of Hospitals (JREC 356/15). Informed consent was obtained from all participants enrolled into the study.

\section{Study design and study site}

The study was a cross-sectional study conducted at Parirenyatwa Group of Hospitals Opportunistic Infections Clinic, Harare, Zimbabwe, between 1 December 2015 and 1 April 2016.

\section{Study subjects}

All HIV patients (18 years and older) on antiretroviral therapy attending Parirenyatwa Group of Hospitals Opportunistic Infections Clinic between 1 December 2015 and 19 February 2016 were given information on the study. Only those who consented to participate in the study were recruited.

\section{Data collection}

Demographic data was obtained from patients by administration of questionnaires to all patients who gave informed consent. The patients' clinical records were accessed from Parirenyatwa Group of Hospitals Opportunistic Infections Clinic database to confirm information given by the patient. Blood samples were collected into ethylenediaminetetraacetic acid (EDTA) tubes.

\section{Sample analysis}

The samples were then stored at $2^{\circ} \mathrm{C}$ to $8^{\circ} \mathrm{C}$ for not more than 7 days before analysis on a Mispa-i2 Chemistry Analyser using the nephelometry method. The assay kits and standards employed for the measurements were supplied by Agappe Biomedical Company Limited (Switzerland). The calibration of the analyser was provided in the smart card of the analyzer. Control samples were assayed every day before samples were assayed for glycosylated haemoglobin (HbA1c).

\section{Data analysis}

Data was captured using Microsoft Excel, normally distributed variables were summarised using the mean, standard deviation and $95 \%$ confidence interval, and skewed distributed variables were summarized using median and inter-quartile ranges. Analysis of the data was done using SPSS 23 statistical package.

\section{Case definition}

Diabetes mellitus was diagnosed as a $\mathrm{HbAlc}$ of $\geq 6.5 \%$, pre-diabetes as a $\mathrm{HbA} 1 \mathrm{c}$ of 6.0 $6.4 \%$ and non diabetes as $\mathrm{HbA} 1 \mathrm{c}$ of $<6.0 \%(6)(7)$. 


\section{Results}

A total of $60 \mathrm{HIV}$ patients on antiretroviral therapy were recruited into the study, 33 (55\%) were females and $27(45 \%)$ were males. The mean age was $43.48 \pm 10.3$ years. Nineteen (31.7\%) of the participants were hypertensive and of these 9 were females and 10 were males.

Eighteen percent of the patients had a family history of diabetes mellitus. Majority of the patients $(33.3 \%)$ were on tenofovir, lamivudine and efavirenz.

Table 1. To show prevalence of diabetes mellitus among HIV patients

\begin{tabular}{|l|l|l|}
\hline Category & $\begin{array}{l}\text { Number of } \\
\text { patients }\end{array}$ & Percent (\%) \\
\hline Diabetes mellitus & 5 & 8.3 \\
\hline Pre-diabetes & 13 & 21.7 \\
\hline Non diabetic & 42 & 70.0 \\
\hline
\end{tabular}

Table 1 shows that the prevalence of diabetes mellitus was $8.3 \%$ whilst $70 \%$ of the patients were non diabetic.

Table 2. To show the relationship between diabetes mellitus and antiretroviral therapy

\begin{tabular}{|l|l|l|l|}
\hline $\begin{array}{l}\text { Antiretroviral therapy } \\
\text { treatment }\end{array}$ & $\begin{array}{l}\text { Number of } \\
\text { patients on } \\
\text { combination }\end{array}$ & $\begin{array}{l}\text { Number } \\
\text { of } \\
\text { diabetes } \\
\text { mellitus } \\
\text { patients }\end{array}$ & $\begin{array}{l}\text { Percent of the } \\
\text { patients with } \\
\text { diabetes } \\
\text { mellitus (\%) }\end{array}$ \\
\hline $\begin{array}{l}\text { Atazanavir, lamivudine } \\
\text { and ritonavir }\end{array}$ & 9 & 0 & 0 \\
\hline $\begin{array}{l}\text { Zidovudine, lamivudine } \\
\text { and nevirapine }\end{array}$ & 5 & 0 & 0 \\
\hline $\begin{array}{l}\text { Abacavir, lamivudine, } \\
\text { atazanavir and ritonavir }\end{array}$ & 3 & 0 & 0 \\
\hline $\begin{array}{l}\text { Tenofovir, lamivudine and } \\
\text { efavirenz }\end{array}$ & 20 & 1 & 5 \\
\hline $\begin{array}{l}\text { Zidovudine, lamivudine, } \\
\text { tenofovir and atazanavir }\end{array}$ & 6 & 0 & 0 \\
\hline $\begin{array}{l}\text { Tenofovir, lamivudine and } \\
\text { nevirapine }\end{array}$ & 5 & 1 & 20 \\
\hline $\begin{array}{l}\text { Zidovudine, } \\
\text { lamivudineand ritonavir }\end{array}$ & 7 & 1 & 14.3 \\
\hline $\begin{array}{l}\text { Zidovudine, lamivudine } \\
\text { and efavirenz }\end{array}$ & 5 & 2 & 40 \\
\hline
\end{tabular}

Table 2 shows that HIV patients on zidovudine, lamivudine and efavirenzantiretroviral therapy had a higher proportion of patients with diabetes mellitus. There were no patients with diabetes mellitus in patients receiving Atazanavir, lamivudine and ritonavir; zidovudine, lamivudine and nevirapine; abacavir, lamivudine, atazanavir and ritonavir and zidovudine, lamivudine, tenofovir and atazanavir.

\section{Discussion}

The etiology of glucose disorders in HIV patients is unknown and it has not been directly confirmed that HIV infection may cause hyperglycaemia. Whilst antiretroviral drugs have a direct role in pathogenesis of hyperglycaemia in HIV patients and some studies indicate that HIV disease may also be associated with the development of hyperglycaemia (4). An increased risk of diabetes mellitus in HIV infected individual on antiretroviral drug treatment when compared to HIV infected individuals not on antiretroviral drug treatment has been reported (8). 
Texila International Journal of Public Health

Volume 5, Issue 1, Mar 2017

The prevalence of diabetes mellitus was $8.3 \%$. The results a similar to the reported prevalence of diabetes mellitus amongst patients on zidovudine, lamivudine and nevirapine of $10.3 \%$ and $7.1 \%$ amongst patients on tenofovir, lamivudine and efavirenz in Ethopia (9). The prevalence of diabetes mellitus amongst patients on antiretroviral therapy was higher than $2.2 \%$ reported in South Africa (10). However the prevalence of diabetes mellitus was lower than $18 \%$ reported Tanzania (11).

We note that majority of the patients were on efavirenz containing regimen. Association between efavirenz exposure and diabetes mellitus has been reported. However is part of the first line of antiretroviral therapy treatment in sub Saharan Africa due to its perceived lower toxicity when compared to nevirapine (5). As antiretroviral access increases in sub Saharan Africa incidence of HIV associated diabetes mellitus is bound to grow (9)leading to an increase in diabetes mellitus prevalence.

Pre-diabetes produces no symptoms but it is a risk for the development of type 2 diabetes mellitus. The pre-diabetesperson is 5 to 15 times more likely to develop type 2 diabetes mellitus as compared to a person with normal blood glucose(12). The prevalence of prediabetes was $21.7 \%$ which is similar to the prevalence of pre-diabetes reported in Ethiopia of $22.4 \%(12)$.

Health care professional need working in HIV clinic need to create awareness to their HIV infected patients on diabetes mellitus prevention, diagnosis and treatment (9). We note the limitation of the small sample size and also the small number of patients with diabetes mellitus which did not enable us to carry association analysis.

\section{Conclusion}

Diabetes mellitus prevalence amongst the HIV patients on antiretroviral therapy treatment was $8.3 \%$. There is need for need to investigate the factors associated with diabetes mellitus in HIV patients on antiretroviral therapy treatment and confirm the prevalence in a study with a large sample size.

\section{References}

[1]. Dave JA, Lambert EV, Badri M, West S, Maartens G, Levitt NS. Effect of nonnucleoside reverse transcriptase inhibitor-based antiretroviral therapy on dysglycemia and insulin sensitivity in South African HIV-infected patients. JAIDS J Acquir Immune DeficSyndr. 2011; 57 (4):284-9.

[2]. Gebreyesus HA. Prevalence of prediabetes in HIV-1 infected adults receiving antiretroviral therapy in Addis Ababa, Ethiopia. Int J PharmaSci Res. 2015; 6 (2):440-3.

[3]. Haregu TN, Olenburg B, Setswe G, Elliott J, Nanayakkara V. Epidemiology of Comorbidity of HIV/AIDS and Non---communicable Diseases in Developing Countries: A systematic review. J Glob Health Care Syst. 2012; 2 (1).

[4]. Mohammed AE, Yemane Shenkute T, ChenekeGebisa W. Diabetes mellitus and risk factors in human immunodeficiency virus-infected individuals at Jimma University Specialized Hospital, Southwest Ethiopia. Diabetes MetabSyndrObes Targets Ther. 2015 Apr; 197.

[5]. Maganga E, Smart LR, Kalluvya S, Kataraihya JB, Saleh AM, Obeid L, et al. Glucose Metabolism Disorders, HIV and Antiretroviral Therapy among Tanzanian Adults. Pacheco AG, editor. PLOS ONE. 2015 Aug 19; 10(8):e0134410.

[6]. Manning K, Senekal M, Harbron J. Non-communicable disease risk factors and treatment preference of obese patients in Cape Town. Afr J Prim Health Care Fam Med. 2016; 8(1):1-12.

[7]. Monroe AK, Glesby MJ, Brown TT. Diagnosing and Managing Diabetes in HIV-Infected Patients: Current Concepts. Clin Infect Dis. 2015 Feb 1; 60 (3):453-62.

[8]. Moyo D, Tanthuma G, Mushisha O, Kwadiba G, Chikuse F, Cary MS, et al. Diabetes mellitus in HIV-infected patients receiving antiretroviral therapy. SAMJ South Afr Med J. 2014; 104 (1):40-2.

[9]. Rasmussen LD, Mathiesen ER, Kronborg G, Pedersen C, Gerstoft J, Obel N. Risk of Diabetes Mellitus in Persons with and without HIV: A Danish Nationwide Population-Based Cohort Study. Atashili J, editor. PLoS ONE. 2012 Sep 12; 7 (9):e44575. 
Texila International Journal of Public Health

Volume 5, Issue 1, Mar 2017

[10]. Shen Y, Wang Z, Liu L, Zhang R, Zheng Y, Lu H. Prevalence of hyperglycemia among adults with newly diagnosed HIV/AIDS in China. BMC Infect Dis. 2013; 13 (1):79.

[11]. The International Expert Committee. International Expert Committee Report on the Role of the A1C Assay in the Diagnosis of Diabetes. Diabetes Care. 2009 Jul 1; 32 (7):1327-34.

[12]. World Health Organization. Use of glycated haemoglobin (HbAlc) in diagnosis of diabetes mellitus: abbreviated report of a WHO consultation. 2011 [cited 2016 Oct 28]; Available from: http://apps.who.int/iris/handle/10665/70523 